\title{
Determination of lysosomal exoglycosidases in human saliva
}

\author{
Sylwia Chojnowska', Anna Zalewska², Małgorzata Knaś3, Napoleon Waszkiewicz ${ }^{4}$, \\ Danuta Waszkiel2 ${ }^{2}$, Agnieszka Kossakowska ${ }^{5}$ and Krzysztof Zwierz ${ }^{5 凶}$
}

'Medical Institute, College of Computer Science and Business Administration, Lomza, Poland; 2 Department of Conservative Dentistry, Medical University in Bialystok, Poland; ${ }^{3}$ The Institute of Health Care, The Higher Vocational School, Suwalki, Poland; ${ }^{4}$ Department of Psychiatry, Medical University in Bialystok, Poland; ${ }^{5}$ Medical College of the Universal Education Society, Lomza, Poland

\begin{abstract}
Background: Currently we observe a growing interest in human saliva as a non-invasive material for diagnosis and monitoring of general and oral diseases. Methods: The aim of our study was adaptation of the Marciniak et al. (Marciniak J, Zalewska A, Popko J, Zwierz K, 2006, Clin Chem Lab Med 44: 933-937) method for determination of HEX and GLU activity in synovial fluid, and for determination of: HEX and GLU, as well as MAN, GAL, and FUC activity in human saliva. Results: Under optimal conditions, $10 \mu \mathrm{l}$ of saliva for HEX, and $30 \mu \mathrm{l}$ for GLU, MAN, GAL and FUC, were sufficient for determination of human salivary exoglycosidases activity with variation coefficient ranging from 0.89 for GLU to 0.99 for GAL. Conclusion: The adapted method for exoglycosidases activity determination in human saliva is sufficiently sensitive and precise to use in clinical diagnosis.
\end{abstract}

Key words: $\beta$-galactosidase, $\beta$-glucuronidase, $\alpha$-fucosidase, a-mannosidase, $\mathrm{N}$-acetyl- $\beta$ - $\mathrm{D}$-hexosaminidase, saliva

Received: 08 September, 2013; revised: 20 January, 2014; accepted: 25 February, 2014; available on-line: 18 March, 2014

\section{INTRODUCTION}

Salivary exoglycosidases are a group of enzymes that are responsible for degradation of oligosaccharide chains of glycoconjugates during organogenesis, growth and normal tissue turnover. Glycoconjugates - include glycoproteins and glycolipids, constituting cellular membranes, for e.g. in salivary gland cells and oral mucosa as well as heteropolysaccharide chains of glycosaminoglycans and proteoglycans constituting extracellular matrix with glycoproteins (Zwierz et al., 1989). Glycoconjugate catabolism depends on continuous renewal of cellular elements, it is started by endoglycosidases and then successively cleaved at the non-reducing end of oligosaccharide chains by exoglycosidases (Zwierz et al., 1989; Winchester, 2005). Activity of exoglycosidases in saliva is normally quite low. Elevation of specific activities of salivary exoglycosidases may indicate a loss in equilibrium between degradation of older and synthesis of newest elements, which is observed in different pathological states of salivary glands (Knaś et al., 2006; Waszkiewicz et al., 2008; Waszkiewicz et al., 2009).

There were different methods described for exoglycosidase activity determination based on different substrates, e.g sugar derivatives of 4-nitrophenol (Knaś et al., 2006), phenolphthalein (Lamster et al., 1987) and 4-meth- ylumbelliferone (Lamster et al., 2003) for determination of the salivary exoglycosidases activitiy. We determined activity of salivary lysosomal enzymes by the method of Marciniak et al. (Marciniak et al., 2006), based on 4-nitrophenol derivatives of appropriate sugars, specifically for synovial fluid HEX and GLU. Increasing interest in the activity of salivary exoglycosidases persuaded us to standardize a method for the determination of activity of majority of salivary exoglycosidases utilizing 4-nitrophenol derivatives of the appropriate sugars. We have previously found elevated activity of HEX and its isoenzymes in synovial fluid and serum of the patients with different arthropathies (Popko et al., 2006), and selected saliva of women with rheumatoid arthritis, as the incidence of rheumatoid arthritis is three times higher in women than in men (Zalewska et al., 2013).

In the current study we present kinetics and optimal conditions for measuring the activity of lysosomal FUC, GAL, GLU, HEX and MAN in human saliva, applicable for clinical diagnosis.

\section{MATERIALS AND METHODS}

Experimental. Forty rheumatoid arthritis (RA) from the Rheumatology and Internal Disease Department, Medical University in Bialystok (Poland) and forty generally healthy women, matched in age and exclusion criteria to the RA group, recruited at the Department of Conservative Dentistry Medical University in Bialystok, Poland, participated in the study. All RA women fulfilled the American College of Rheumatology revised criteria for RA. The study was conducted at the University Hospital in Bialystok, Poland. The survey was carried out between April 2007 and September 2010. Patients were excluded if they smoked or used medication which could cause oral or eye dryness. None of the patients had diabetes mellitus or hypertension. Patients with HCV and HIV infection as well as with periodontitis or gingivitis were also excluded.

Written informed consent was obtained from each patient, after the aims and methodology of the study were explained. The study was approved by the Ethics Committee of the Medical University of Bialystok (permission number R-I-002/282/2007).

e-mail: kszwie@gmail.com

Abbreviations: HEX, N-acetyl- $\beta$-D-hexosaminidase; MAN, a-mannosidase; FUC, a-fucosidase; GAL, $\beta$-galactosidase; GLU, $\beta$-glucuronidase; RA, rheumatoid arthritis; UWS, unstimulated whole saliva 
Unstimulated whole saliva (UWS) collection: Subjects were instructed to refrain from food and beverages, except water, for two hours before saliva collection. To minimize circadian influences, all salivary samples were collected between 8 a.m. and 10 a.m. During sample collection patients were protected from any stimulation. The whole saliva was collected by passive spitting into plastic container, placed on crushed ice, always assisted by the same person (A.Z). Immediately after collection, salivary samples were centrifuged at $3000 \times g$ for 20 minutes at $4^{\circ} \mathrm{C}$, to remove cells and debris. The resulting supernatants were divided and transferred to plastic test tubes (Eppendorf type), frozen and kept at $-80^{\circ} \mathrm{C}$, until analyzed.

Enzyme substrates: As a substrate for determination of the HEX activity, 4-nitrophenyl-N-acetyl$\beta$-glucosaminide (Sigma, St. Louis, MO, USA) was used, as well as 4-nitrophenyl- $\beta$-D-glucuronide (Fluka Chemie; Sigma, St. Louis, MO, USA) for $\beta$-GLU and 4-nitrophenyl- $\beta$-D-galactopyranoside (Sigma) for $\beta$-GAL, 4-nitrophenyl- $\alpha$-D-fucopyranoside (Sigma) for $\alpha$-FUC and 4-nitrophenyl- $\alpha$-D-mannopyranoside for
$\alpha$-MAN (Sigma). The calibrant, 4-nitrophenol (Sigma), was prepared at concentration of $0.3 \mathrm{mM}$ in $100 \mathrm{mM}$ citrate-phosphate buffer, $\mathrm{pH} 4.7$.

Instrumentation. Spectrophotometric measurements were carried out using a MR-96 A microplate reader (Mindray, Shenzhen, ChRL) at $405 \mathrm{~nm}$, and immunosorbent assays plates of 96 wells (MaxiSorp; Nunc Intermed, Copenhagen, Denmark).

Statistical analysis. Statistical analysis was performed with Statistica 9.0 using $t$-Student test (StatSoft, Cracov, Poland). Results were presented as mean and S.D.

\section{RESULTS}

\section{Calibration}

Activity of HEX, GAL, MAN, FUC and GLU in the samples was analyzed using a calibration curve for 4-nitrophenol. Calibration curve was obtained by adding 200 $\mathrm{mM}$ borate buffer, $\mathrm{pH} 9.8$ to standard solution of 4 -nitrophenol, and intensity of the yellow color produced was measured at $405 \mathrm{~nm}$ with a microplate reader.
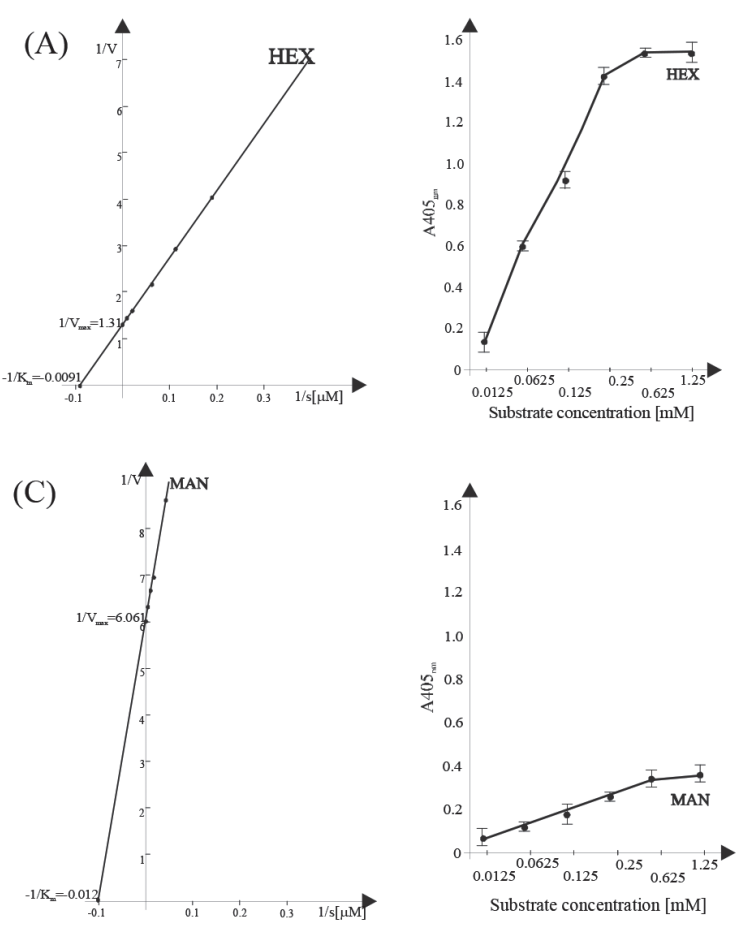

(E)
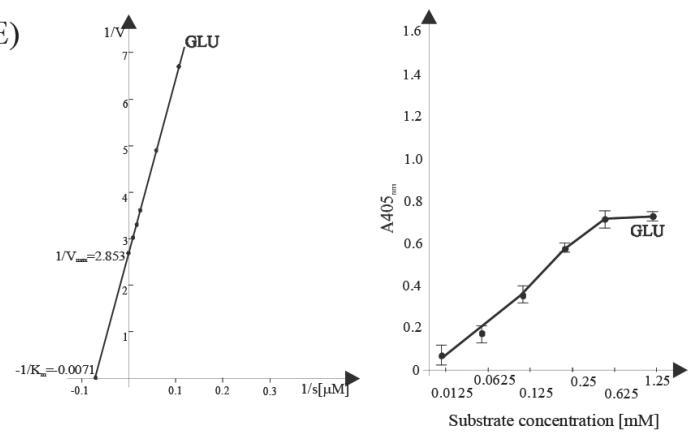
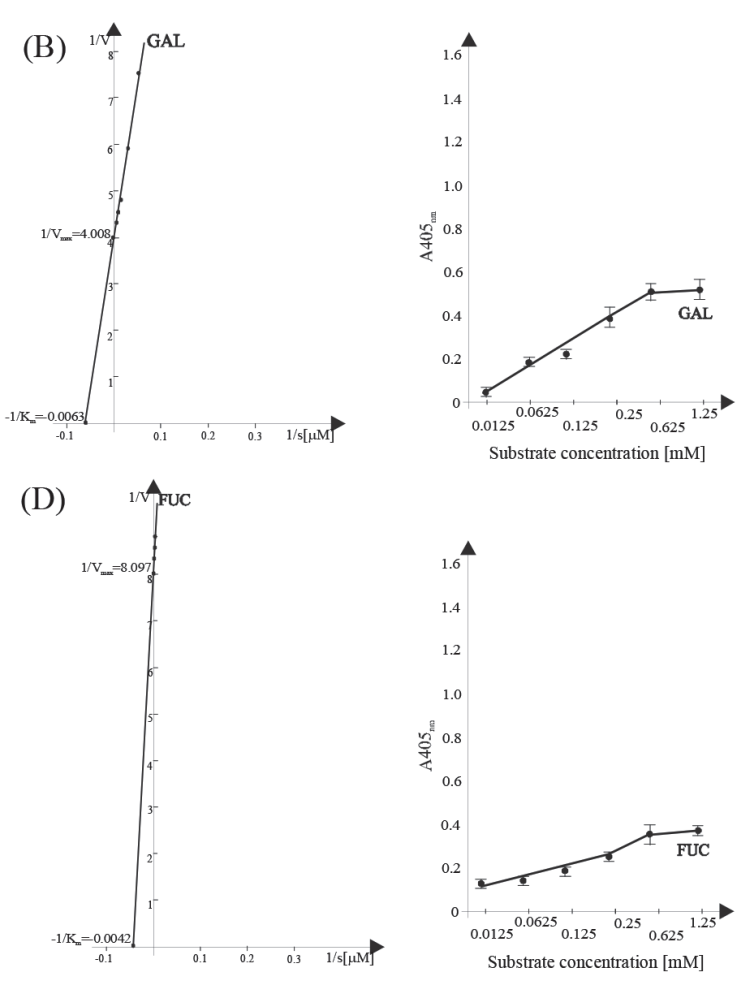

Figure 1. Lineweaver-Burk and Michaelis-Menten plots for determination of $K_{\mathrm{m}}$ for HEX, GLU, GAL, MAN and FUC (mean values of 40 measurements \pm S.D.). 


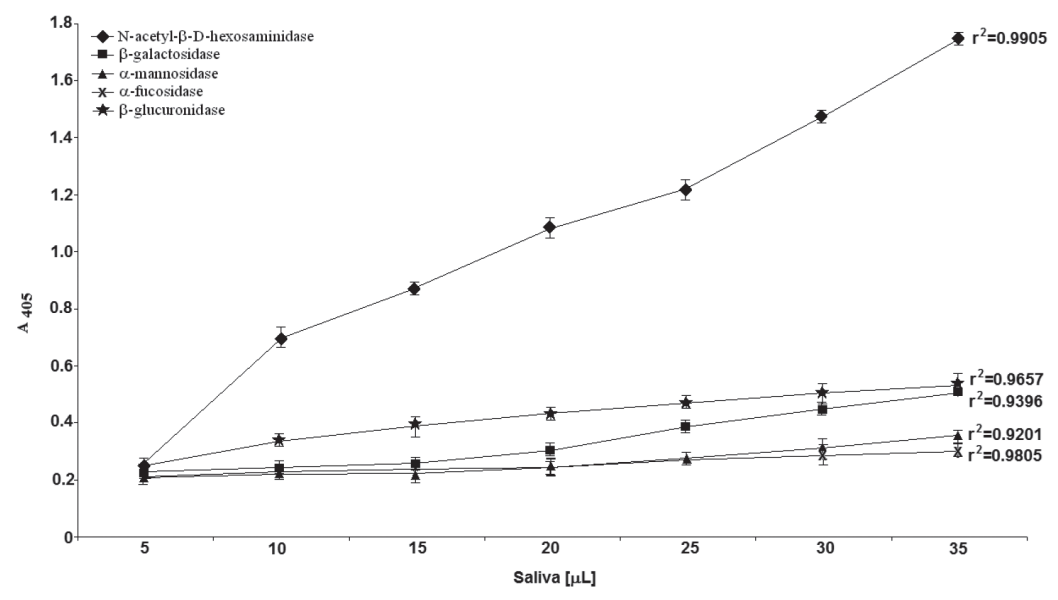

Figure 2. Effect of enzyme amount on HEX, GLU, GAL, MAN and FUC activities (mean values of 40 measurements \pm S.D.).

\section{Substrate concentration}

For the determination of salivary exoglycosidases Km, to $10 \mu \mathrm{l}$ of UWS for HEX and $30 \mu \mathrm{l}$ of UWS for GAL, GLU, MAN, and FUC, $30 \mu \mathrm{l}$ of substrate was added at the concentrations indicated at Fig. $1 \mathrm{~A}-1 \mathrm{E}$, and $40 \mu \mathrm{l}$ of $100 \mathrm{mM}$ citrate-phosphate buffer $\mathrm{pH} 4.7$ for HEX, pH 4.3 for GAL, MAN, FUC and $200 \mathrm{mM}$ sodium acetate buffer $\mathrm{pH} 4.5$, for GLU. Microplates were incubated for $60 \mathrm{~min}$ at $37^{\circ} \mathrm{C}$ with constant shaking. Reactions were stopped by adding $200 \mu \mathrm{l}$ of $200 \mathrm{mM}$ borate buffer, $\mathrm{pH}$ 9.8. The $K_{\mathrm{m}}$ value calculated was: $0.11 \mathrm{mM}$ for HEX (Fig. 1A), $0.16 \mathrm{mM}$ for GAL (Fig. 1B) for GAL, 0.08 $\mathrm{mM}$ for MAN (Fig. 1C), $0.23 \mathrm{mM}$ for FUC (Fig. 1D), $0.14 \mathrm{mM}$ for GLU (Fig. 1E).
Effect of the amount of saliva in the incubation mixture: To evaluate influence of the amount of saliva on activity of salivary exoglycosidases, volumes of 5-30 $\mu$ l of UWS, $30 \mu l$ of substrate at concentration $1.1 \mathrm{mM}$ (HEX), $1.6 \mathrm{mM}$ (GAL), $1.4 \mathrm{mM}$ (GLU), $0.8 \mathrm{mM}$ (MAN), $2.3 \mathrm{mM}$ (FUC) and appropriate amount of $100 \mathrm{mM}$ citrate-phosphate buffer $\mathrm{pH} 4.7$ (HEX), $\mathrm{pH} 4.3$ (FUC, GAL, MAN) or $200 \mathrm{mM}$ sodium acetate buffer $\mathrm{pH} 4.5$ (GLU), to obtain $100 \mu \mathrm{L}$ of total fluid in the well, were added to microplate wells. Microplates were incubated for $60 \mathrm{~min}$ at $37^{\circ} \mathrm{C}$, with constant shaking, and reactions were stopped by adding $200 \mu \mathrm{l}$ of $200 \mathrm{mM}$ borate buffer, $\mathrm{pH}$ 9.8. Relation between amount of saliva and $A_{405 \mathrm{~nm}}$ of the released 4-nitrophenol by particular exoglycosidase is presented in Fig. 2.

Effect of $\mathrm{pH}$ on the enzyme activity: Salivary exoglycosidase activity was examined at $\mathrm{pH} 3.5-5.5$ at a substrate concentration of $1.1 \mathrm{mM}$ (HEX), $1.6 \mathrm{mM}$ (GAL), $0.8 \mathrm{mM}$ (MAN), $2.3 \mathrm{mM}$ (FUC) and $1.4 \mathrm{mM}$ (GLU) (Fig. 3). Exoglycosidase activity was determined as described above. Majority of lysosomal enzymes demonstrate optimal activity in a slightly acidic environment, and their activity diminishes at neutral $\mathrm{pH}$. We demonstrated that HEX, the most active of exoglycosidases (Zwierz et al., 1989), has optimum at pH 4.7 (Fig. 3A), GLU at pH 4.5 (Fig. 3A), and GAL, MAN, FUC at pH 4.3 (Fig. 3B), respectively.
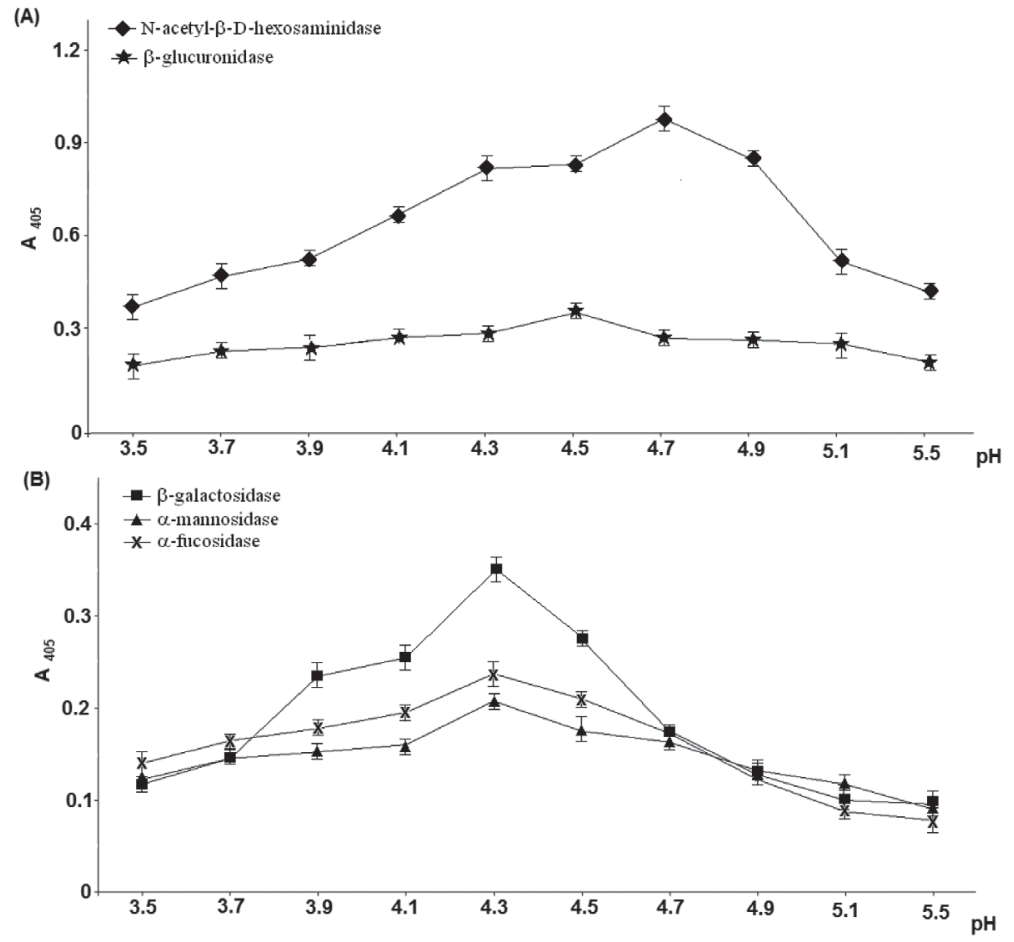

Figure 3. Effect of pH on: (A) HEX, GLU, (B) GAL, MAN and FUC activities (mean values of 40 measurements \pm S.D.).

\section{Incubation time}

To establish optimal incubation time we used concentrations of substrates as in Fig. 4, and 10 $\mu \mathrm{l}$ of UWS for HEX and $30 \mu \mathrm{l}$ of UWS for the remaining exoglycosidases. Samples were incubated between 0 and $120 \mathrm{~min}$ (Fig. 4).

Determination of exoglycosidase activity in human saliva: We propose the following procedure for determination of salivary FUC, GAL, GLU, HEX and MAN activity in 96 wells assays plates.

Into each microplate well, 10 $\mu \mathrm{l}$ of saliva for HEX and $30 \mu \mathrm{l}$ of saliva for FUC, GAL, MAN and GLU was added, as well as $30 \mu$ l of substrate at concentration: $1.1 \mathrm{mM}$ (HEX), $1.6 \mathrm{mM}$ (GAL), $1.4 \mathrm{mM}$ (GLU), $0.8 \mathrm{mM}$ (MAN) and $2.3 \mathrm{mM}$ (FUC), as well as $40 \quad \mu \mathrm{l}$ of $100 \mathrm{mM}$ citrate-phosphate buffer $\mathrm{pH} 4.7$ (HEX), pH 4.3 (GAL, MAN, FUC) and sodium acetate buffer pH 4.5 (GLU). Unless otherwise indicated, incubation was carried out for $60 \mathrm{~min}$ at $37^{\circ} \mathrm{C}$, with 

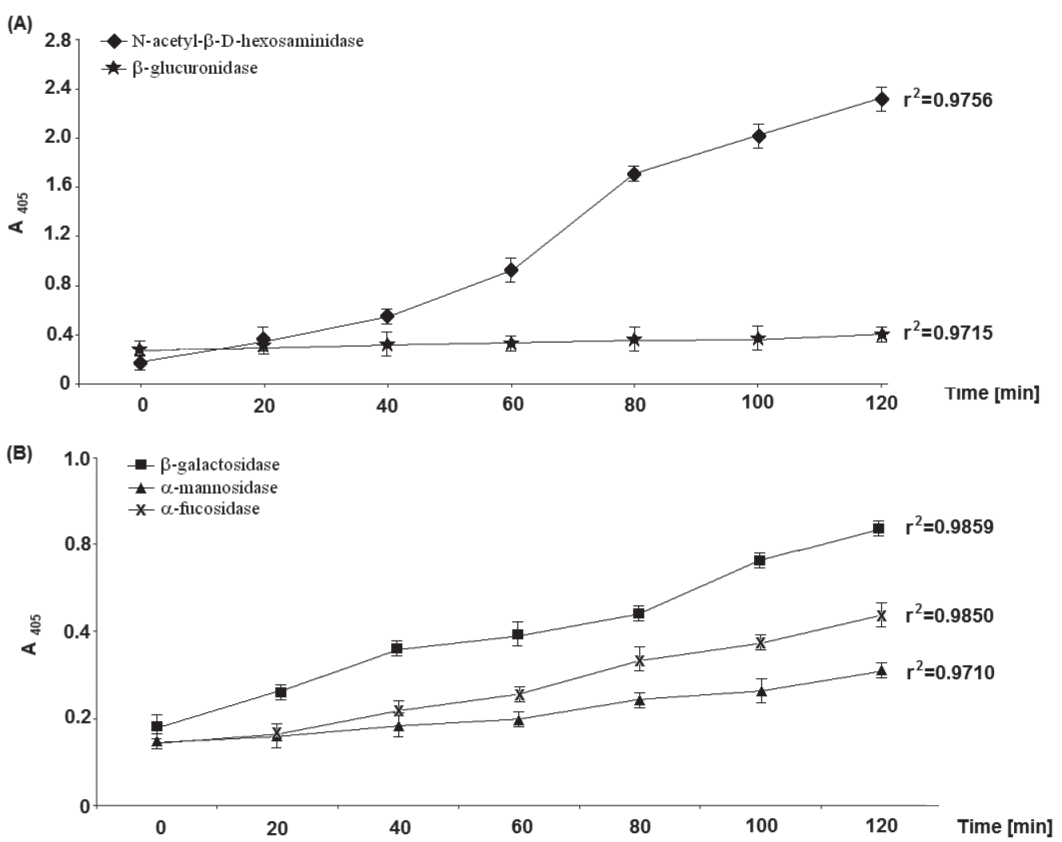

Figure 4. Effect of incubation time on (A) HEX, GLU, (B) GAL, MAN and FUC activities (mean values of 40 measurements \pm S.D.). constant shacking; the reaction was stopped by adding $200 \mu \mathrm{L}$ of $200 \mathrm{mM}$ borate buffer $\mathrm{pH} 9.8$. The A $405 \mathrm{~nm}$ was determined with Elx800TM microplate reader (MR-96 A, Mindray).

\section{Precision}

Intra-assay variability was assayed using human saliva from a patient with RA. The activity was measured 20 times in each sample. Activity and standard deviation was estimated to be: 16.8 $\mathrm{pKat} / \mathrm{mL} \pm 0.61$ for HEX, 2.53 $\mathrm{pKat} / \mathrm{mL} \pm 0.4$ for GAL, 2.78 $\mathrm{pKat} / \mathrm{mL} \pm 0.66$ for MAN, 1.56 $\mathrm{pKat} / \mathrm{mL} \pm 0.31$ for FUC and $1.24 \mathrm{pKat} / \mathrm{mL} \pm 0.36$ for GLU. The coefficient of variation was: $0.932 \%$ for HEX, $0.99 \%$ for GAL, $0.989 \%$ for MAN, $0.956 \%$ for FUC and $0.89 \%$ for GLU.

RA versus the reference group: In the saliva of RA patients activities of all of the examined exoglycosidases were significantly higher in comparison to the reference group (Fig. 5).
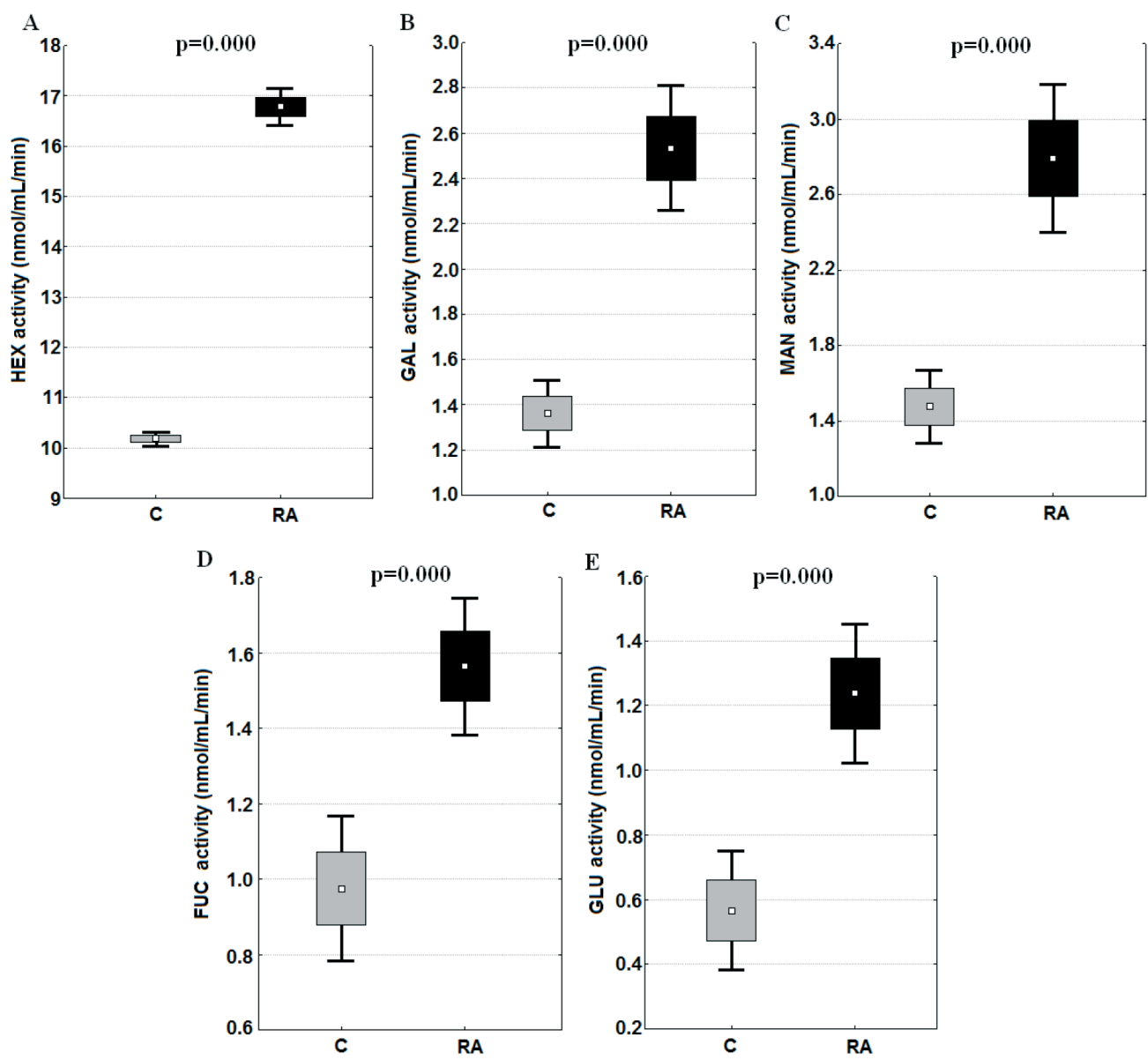

Figure 5. Activities of salivary exoglycosidases of $40 \mathrm{RA}$ and 40 healthy women.

$C$ - control; RA - rheumatoid arthritis. A - HEX, B - GAL, C - MAN, D - FUC, E - GLU. 


\section{DISCUSSION}

It was reported that lysosomal exoglycosidases take part in homeostasis of oral cavity and changes in their activities reflect oral health. The first reports on salivary exoglycosidases were focused mainly on association of salivary exoglycosidases and periodontal disease. Nakamura and Slots (Nakamura \& Slots, 1983) showed that severity of the periodontal disease positively correlated with the increase in activities of lysosomal HEX, $\alpha$ - and $\beta$-GAL, $\alpha$ - and $\beta$-GLU, $\alpha$ - and $\beta$-glucosidase as well as $\alpha$ - and $\beta$-MAN. Zambon et al. (Zambon et al., 1985) claimed that the determination of the activities of salivary $\beta$-GAL, $\beta$-GLU and $\alpha$-glucosidases might be helpful in monitoring periodontal status after successful surgical treatment.

Recently, more attention is paid to determination of salivary exoglycosidases activity in diagnostics of general diseases. It was also shown that changes in the salivary exoglycosidases activities may be related to changes in the ultrastructure and function of the salivary glands. Bierć et al. (Bierć et al., 2010) reported significant increase in activities of GLU, GAL, and HEX and its isoenzymes, in salivary gland tissue of patients with salivary glands tumors. Authors hypothesized that salivary exoglycosidases may take part in tumor development and metastasis. Knaś et al. (Knaś et al., 2006) reported that combination of diabetes and smoking gives significant increase in the specific activity of salivary HEX and its isoenzymes. Waszkiewicz et al. (Waszkiewicz et al., 2008) suggested that significant increase in salivary HEX and its isoenzymes activity after large single dose of ethanol, can be a marker of the harmful level of drinking, which is damaging salivary glands and/or oral mucosa. Authors claimed that since the activity of isoenzyme A reflects the secretory status of the cell (Waszkiewicz et al., 2013), the significant increase of HEX A activity in saliva, suggests that increased production of HEX A is related to functional changes in salivary glands cells after harmful drinking. The activity of HEX B is an outcome of breakdown of the cell membrane (Waszkiewicz et al., 2013), so significant increase in HEX B specific activity in saliva may be an indicator of advanced pathological changes in the structure of the salivary glands cells. Results of the present study show that increase in the catabolism of glycoconjugates of the salivary gland connective tissue (expressed as elevated activity of the salivary exoglycosidases) is more pronounced in the case of RA patients in comparison to the reference group. These changes in salivary exoglycosidases activities may be related to changes in the ultrastructure and function of the salivary glands.

As saliva is more and more frequently used as a non-invasive diagnostic material, we decided to standardize determination of five salivary exoglycosidases activities utilizing 4-nitrophenol derivatives of appropriate sugars, by adaptation to saliva of the Marciniak et al., (Marciniak et al., 2006) method for exoglycosidases determination in synovial fluid. Since assays for enzymes activity determination are recommended to be carried out at a substrate concentration that is approximately 10 times higher than $K_{\mathrm{m}}$ of the enzyme (Dixon et al., 1979), we determined $K_{\mathrm{m}}$ to be: $0.11 \mathrm{mM}$ for HEX , $0.16 \mathrm{mM}$ for GAL, $0.08 \mathrm{mM}$ for MAN, $0.23 \mathrm{mM}$ for FUC and $0.14 \mathrm{mM}$ for GLU. In the routine determination of salivary exoglycosidase activity we use the substrate concentration for all enzymes that is 10 times higher than their $K_{\mathrm{m}}$.

Our results are in agreement with previously published papers that majority of lysosomal exoglycosidases are ac- tive at slightly acidic $\mathrm{pH}$, and HEX is the most active of exoglycosidases in tissues (Zwierz et al., 1999; Popko et al., 2008). Optimal $\mathrm{pH}$ of salivary exoglycosidases was ranging from 4.3 for GAL, MAN, FUC, through 4.5 for GLU, to 4.7 for HEX.

We are presenting proof that $10 \mu$ l of saliva is sufficient for the determination of salivary activity of HEX, and $30 \mu \mathrm{L}$ of saliva is appropriate for determination of activities of the remaining exoglycosidases.

\section{CONCLUSION}

Adapted method for determination of activity of lysosomal exoglycosidases in human saliva is sufficiently sensitive and precise to use in clinical diagnosis of salivary glands and oral health.

\section{Acknowledgements}

We are grateful to Dr T. Merry from the Manchester University, England for the critical reading of the manuscript.

This study was supported by grant of the Medical University of Białystok No 134-47731 L.

\section{Conflict of interest}

We declare that there are no conflicts of interest, funding, employment or leadership and honorarium.

\section{REFERENCES}

Bierć M, Minarowski Ł, Woźniak Ł, Chojnowska S, Knaś M, Szajda SD et al (2010) The activity of selected glycosidases in salivary gland tumors. Folia Histochem Cytobiol 48: 471-474.

Dixon M, Webb EC, Thorne JC, Tipton KF (1979) Ensymes. Longman, London.

Knaś M, Karaszewska K, Szajda SD, Zarzycki W, Dudzik D, Zwierz K (2006) Saliva of patients with Type I diabetes: effect of smoking on activity of lysosomal exoglycosidases. Oral Dis 12: 278-282.

Lamster IB, Harper DS, Fiorello LA, Oshrain RL, Celenti RS, Gordon JM (1987) Lysosomal and cytoplasmic enzyme activity, crevicular fluid volume, and clinical parameters characterizing gingival status and shallow to intermediate probing depths. J. Periodontol 58: 614621.

Lamster IB, Kaufman E, Grbic JT, Winston LJ, Singer RE (2003) $\beta$-glucuronidase activity in saliva: relationship to clinical periodontal parameters. J Periodontol 74: 353-359.

Marciniak J, Zalewska A, Popko J, Zwierz K (2006) Optimization of an enzymatic method for the determination of lysosomal $\mathrm{N}$-acetyl-beta-D-hexosaminidase and beta-glucuronidase in synovial fluid. Clin Chem Lab Med 44: 933-937.

Nakamura M, Slots J (1983) Salivary enzymes. Origin and relationship to periodontal disease. J Periodontol Res 16: 559-569.

Popko J, Marciniak J, Ilendo E, Knaś M, Guszczyn T, Stasiak-Barmuta A et al (2008) Profile of exoglycosidases in synovial cell cultures derived from human synovial membrane. Cell Biochem Biophys 51: 89-95.

Popko J, Marciniak J, Zalewska A, Górska A, Zwierz K, Sierakowski S, Urban M (2006) Activity of N-acetyl-beta-hexosaminidase and its isoenzymes in serum and synovial fluid from patients with different artropathies. Clin Exp Rheumat 24: 690-693.

Waszkiewicz N, Chojnowska S, Zalewska A, Zwierz K, Szulc A, Szajda SD (2013) Salivary hexosaminidase in smoking alcoholics with bad periodontal and dental states. Drug Alcohol Dependence 129: 33-40.

Waszkiewicz N, Szajda SD, Jankowska A, Kępka A, Dobryniewski J, Szulc A et al (2008) The effect of the binge drinking session on the activity of salivary, serum, urinary beta hexosaminidase: Preliminary data. Alcohol and Alcoholism 43: 446-450.

Waszkiewicz N, Szajda SD, Jankowska A, Waszkiewicz M, Kępka A, Konarzewska B et al (2009) Catabolism of salivary glycoconjugates in acute ethanol intoxication. Med Sci Monit 15: 413-417.

Winchester B (2005) Lysosomal metabolism of glycoproteins. Glycobiology 15: 1R-15R.

Zalewska A, Knaś M, Waszkiewicz N, Waszkiel D, Sierakowski S, Zwierz K (2013) Rheumatoid arthritis patients with xerostomia have reduced production of key salivary constituents. Oral Surg Oral Med Oral Pathol Oral Radiol 115: 483-490. 
Zambon J, Nakamura M, Slots J (1985) Effect of periodontal therapy on salivary enzymatic activity. J Periodontol Res 20: 652-659.

Zwierz K, Gindzieński A, Ostrowska L, Stankiewicz-Choroszczucha B (1989) Metabolism of glycoconjugates in human gastric mucosa a review. Acta Med Hung 46: 275-288.
Zwierz K, Zalewska A, Zoch-Zwierz W (1999) Isoenzymes of N-acetyl-beta-hexosaminidase. Acta Biocbim Polon 46: 739-757. 